\title{
Oocyte and sperm donors opinions on the acceptable number of offspring
}

\author{
Gunilla Sydsjö, Claudia Lampic, Marie Bladh and Agneta Skoog Svanberg
}

\section{Linköping University Post Print}

\section{Tweet}

N.B.: When citing this work, cite the original article.

Original Publication:

Gunilla Sydsjö, Claudia Lampic, Marie Bladh and Agneta Skoog Svanberg, Oocyte and sperm donors opinions on the acceptable number of offspring, 2014, Acta Obstetricia et Gynecologica Scandinavica, (93), 7, 634-639.

http://dx.doi.org/10.1111/aogs.12395

Copyright: Informa Healthcare / Wiley: 12 months http://eu.wiley.com/WileyCDA/

Postprint available at: Linköping University Electronic Press

http://urn.kb.se/resolve?urn=urn:nbn:se:liu:diva-109117 
Oocyte and sperm donors' opinions on the acceptable number of offspring.

Gunilla Sydsjö ${ }^{1} \mathrm{PhD}$, Claudia Lampic ${ }^{2} \mathrm{PhD}$, Marie Bladh ${ }^{1} \mathrm{MA}$, Agneta Skoog Svanberg ${ }^{3} \mathrm{PhD}$

${ }^{1}$ Obstetrics and Gynecology, Department of Clinical and Experimental Medicine, Faculty of Health Sciences, Linköping University

${ }^{2}$ Department of Neurobiology, Care Sciences and Society, Karolinska Institutet, Stockholm,

${ }^{3}$ Department of Women's and Children's Health, Uppsala University, Uppsala, Sweden

Correspondence: Gunilla Sydsjö,

Division of Obstetrics and Gynecology, Department of Clinical and Experimental Medicine, Faculty of Health Sciences, Linköping University SE - 58185 Linköping, Sweden Tel: +46132231 67; fax: +4613148156

\section{Email: Gunilla.Sydsjo@lio.se}

Running title: Acceptable number of donor offspring 


\section{Conflict of interest}

The authors report no conflict of interest related to this manuscript. 


\begin{abstract}
Objective: To investigate opinions on the acceptable number of donation offspring in a national cohort of oocyte and sperm donors.
\end{abstract}

Design: A prospective follow-up study on a national cohort of gamete donors.

Setting: Sweden.

Methods: Study-specific questionnaire.

Main outcome measures: Opinion on the acceptable number of offspring from one donor.

Results: About half of both oocyte and sperm donors expressed an opinion that the number of offspring from one donor should be limited to between one and ten, and many donors reported having no firm opinion. When controlling for age, educational level, marital status and biological children, oocyte donors were four times more likely to support an upper limit of five offspring compared to sperm donors. For many sperm and oocyte donors the number of offspring resulting from their donations was unknown (43.2\% oocyte, $47.1 \%$ sperm).

Conclusion: Oocyte donors have more restrictive opinions on the acceptable number of offspring from one donor compared to sperm donors. Donors perform a very humanitarian and societal act when donating their gametes. In the ambition to have safe and trustworthy clinics we need to have well-known regulations to be able to recruit donors in the future.

Keywords: attitude, sperm donor, oocyte donor, offspring

\title{
Key message
}

Oocyte donors have more restrictive opinions on the acceptable number of offspring from one donor compared to sperm donors 


\section{Introduction}

The debate about the number of offspring to be allowed per donor has its foundation in a concern for ethical, genetic, legal, economic and social dimensions of third party reproduction. A recent media report from Denmark revealed that one donor was carrier of a rare dominantly inherited disease and that sperm from that donor were estimated to have resulted in 40-75 offspring (1). Setting a limit on the acceptable number of offspring per donor has been debated both among professionals as well as in the society at large, both before and after this event. Clearly there are many factors to be taken into consideration in formulation of national laws and recommendations on gamete donation treatment. One important factor is the trend towards openness regarding donor offspring's genetic origin, as demonstrated by the increasing number of countries with legislation on identifiable gamete donors. In addition, substantial groups of offspring from anonymous donors are actively seeking contact with their donor and half-siblings, and many donors who donated anonymously are taking active steps to make themselves identifiable to offspring $(2,3)$.

The Swedish legislation on donor insemination (1985) and IVF-treatment with donated gametes (2003) grants offspring conceived as a result of gamete donation the right to be given identifying information about his or her donor. In 2005, the Swedish National Board of Health and Welfare issued guidelines which included the following advisory statement: "Oocytes or sperm from a donor should not be used to result in pregnancies leading to the birth of more than six children". However, when this recommendation was revised in 2010 the Swedish National Board of Health and Welfare removed any reference to the recommended number of children resulting from one donor (4). During the past years, a Swedish national cohort of identity-release oocyte and sperm donors has been followed with the aim of studying psychosocial aspects of donating gametes. Both female and male donors were found to have mature and stable personality characteristics when they were accepted to become donors $(5,6)$ and Skoog Svanberg et al (2013) reported that both men and women were in general satisfied with their contribution as donors (7) .

In the context of identity-release donor programs, there is an urgent need for knowledge about donors' opinions on the acceptable number of offspring from their donation. Thus, the principal aim of the present study was to investigate opinions on the acceptable number of donation offspring in a national cohort of oocyte and sperm donors.

\section{Material and methods}

The Swedish study on gamete donation is a prospective longitudinal study including a consecutively recruited cohort of oocyte and sperm donors. All the infertility clinics performing gamete donation in Sweden, at the University Hospitals in Stockholm, Gothenburg, Uppsala, Umeå, Linkoping, Örebro and Malmö, participate in this multicenter study. The study was approved by the Region Ethical Review Board in Linköping 2012/35631. 2012-11-14.

During 2005-2008, all men and women that were accepted as donors and completed at least one round of donation were approached regarding study participation. The only exclusion criterion was inability to speak and read Swedish. Study participants completed one questionnaire prior to donating and, in the spring of 2013, all sperm and oocyte donors who 
had donated during the preceding five to eight years (average 6.5 years) were asked to participate in a follow-up assessment.

Of 156 eligible sperm donors that were approached, 119 (76\%) accepted participation and completed a baseline questionnaire. At the follow-up assessment some donors were not contacted due to unavailable addresses $(n=9)$ or wish to discontinue study participation $(n=4)$ and a total of $88 / 106(83 \%)$ sperm donors completed the questionnaire.

Of 220 eligible oocyte donors that were approached, 181 agreed to participate in the study and completed a baseline questionnaire. At the follow-up assessment a few donors were not contacted due to unavailable addresses $(n=4)$ or a wish to discontinue study participation $(n=1)$ and a total of 149/176 (85\%) oocyte donors completed the questionnaire.

Stated reasons for refraining from study participation were mainly that taking part would be too personal and/or too time consuming. The reasons for our being unable to locate donors for the follow-up assessment are not known; possible explanations include change of personal identification number, protected identity or emigration. A number of study-specific questions were posed to assess participants' behaviour and opinions regarding gamete donation. Participants were requested to state 1) the number of times they had donated sperm/oocytes, 2 ). if they had donated sperm/oocytes at more than one clinic in Sweden, .3). if they had donated sperm/oocytes abroad, 4). if they had knowledge of the number of offspring from their donation and 5). their opinion of the acceptable number of offspring from one donor. In addition, socio-demographic variables on age and education, marital status and children were collected.

\section{Statistics}

Pearson's Chi-squared statistic was used to analyse socio-demographic background data by gender. It was also used to analyse the respondents' reports on the acceptable number of children after donation by gender, age and presence of biological children. Multiple logistic regression was performed on the acceptable number of children after donation (dichotomized variable: $1-<6$ children vs. $\geq 6$ children) with gender, age, educational level and biological children as predictor variables. All statistical analyses were performed using IBM SPSS version 20 (Armonk, NY, USA). A p-value of $<0.05$ (two-sided) was considered significant.

\section{Results}

Socio-demographic characteristics are presented in Table 1. In comparison with sperm donors, oocyte donors had a lower level of education at acceptance and were, at follow-up, more often married or co-habiting with a partner and had biological children. Some donors also had adoptive children ( 4 sperm donors and 0 oocyte donor) and/or stepchildren ( 7 sperm donors and 12 oocyte donors). Few participants had donated at more than one Swedish clinic ( 3 oocyte donors and 2 sperm donors) or abroad ( 1 oocyte donor and 1 sperm donor). For many sperm and oocyte donors the number of offspring resulting from their donations was unknown (43.2\% oocyte donors, $47.7 \%$ sperm donors, $\mathrm{p}<0.001)$.

Oocyte donors were found to report both more restrictive and more generous opinions about the acceptable number of offspring resulting from one donor compared to sperm donors; a higher percentage of women (33.3\%) than men (12.8\%) expressing the opinion that the number of offspring should be limited to between one and five and a larger group of women $(15.9 \%)$ than men $(2.6 \%)$ expressing the opinion that one should place no limit on the number of offspring (Table 2). About half of both oocyte and sperm donors expressed an opinion that 
the number of offspring from one donor should be limited to between one and ten. A considerable percentage of participants did not have an opinion on the acceptable number of offspring from gamete donation ( $28.0 \%$ oocyte donors and $23.1 \%$ sperm donors).

Table 1. Socio-demographic data on participating sperm $(n=89)$ and oocyte donors $n=146)$

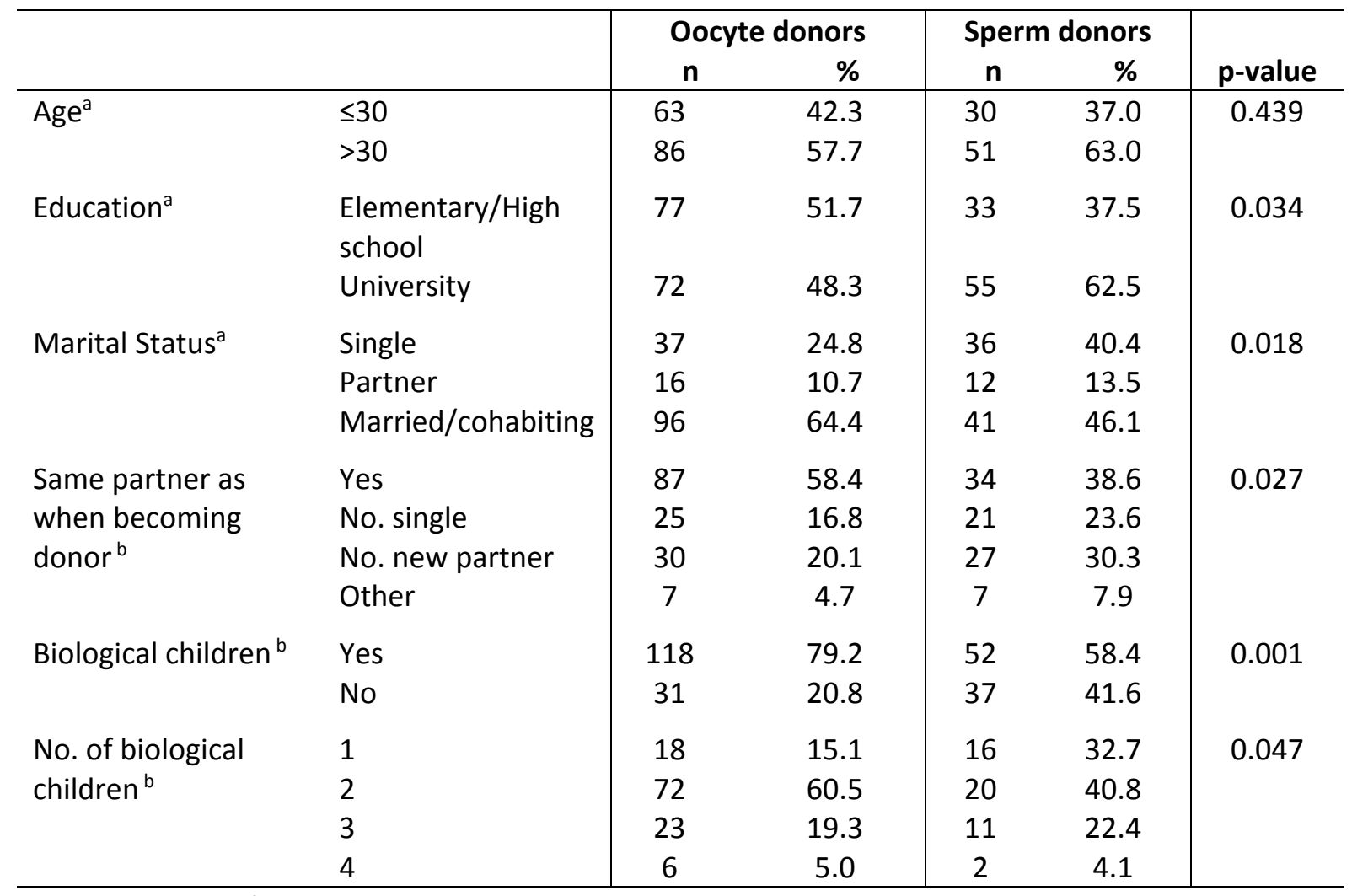

${ }^{a}=$ At acceptance for donation

${ }^{b}=$ At follow-up

Table 2. Opinion on acceptable number of offspring from one donor among sperm and oocyte donors

\begin{tabular}{|c|c|c|c|c|c|c|}
\hline & & \multicolumn{2}{|c|}{ Oocyte donors } & \multicolumn{2}{|c|}{ Sperm donors } & \multirow[b]{2}{*}{ p-value } \\
\hline & & $\mathbf{n}$ & $\%$ & $\underline{n}$ & $\%$ & \\
\hline \multirow[t]{10}{*}{ Acceptable number } & $1-5$ & 44 & 33.3 & 10 & 12.8 & $<0.001^{b}$ \\
\hline & $6-10$ & 23 & 17.4 & 26 & 33.3 & \\
\hline & $11-30+$ & 7 & 5.3 & 22 & 28.1 & \\
\hline & $11-15$ & 2 & 1.5 & 10 & 12.8 & \\
\hline & $16-20$ & 2 & 1.5 & 5 & 6.4 & \\
\hline & $21-25$ & 0 & 0.0 & 0 & 0.0 & \\
\hline & $26-30$ & 1 & 0.8 & 0 & 0.0 & \\
\hline & $>30$ & 2 & 1.5 & 7 & 9.0 & \\
\hline & Unlimited & 21 & 15.9 & 2 & 2.6 & \\
\hline & No opinion ${ }^{a}$ & 37 & 28.0 & 18 & 23.1 & \\
\hline
\end{tabular}

$\mathrm{a}=$ includes unclear responses from 4 oocyte donors and 5 sperm donors

${ }^{b}=$ analysis based on five main categories (1-5, 6-10, 11-30+, unlimited, and no opinion) 
Table 3. Opinion of number of acceptable number of children after donation reported by donors in relation to age and biological children

\begin{tabular}{|c|c|c|c|c|c|c|c|c|c|c|}
\hline & \multicolumn{5}{|c|}{ Age } & \multicolumn{5}{|c|}{ Biological children } \\
\hline & \multicolumn{2}{|c|}{$\leq 30$} & \multicolumn{2}{|c|}{$>30$} & \multirow[b]{2}{*}{ p-value } & \multicolumn{2}{|c|}{ No } & \multicolumn{2}{|c|}{ Yes } & \multirow[b]{2}{*}{ p-value } \\
\hline & $\mathbf{n}$ & $\%$ & $\mathbf{n}$ & $\%$ & & $\mathbf{n}$ & $\%$ & $\mathbf{n}$ & $\%$ & \\
\hline Acceptable number of children after donation & & & & & 0.082 & & & & & 0.047 \\
\hline $1-5$ & 19 & 22.4 & 35 & 25.7 & & 15 & 25.4 & 39 & 27.6 & \\
\hline $6-10$ & 26 & 30.6 & 24 & 17.6 & & 15 & 25.4 & 36 & 20.7 & \\
\hline $11-15$ & 2 & 2.4 & 10 & 7.4 & & 6 & 10.2 & 6 & 3.4 & \\
\hline $16-20$ & 3 & 3.5 & 4 & 2.9 & & 3 & 5.1 & 4 & 2.6 & \\
\hline $21-25$ & 0 & 0.0 & 0 & 0.0 & & 0 & 0.0 & 0 & 0.0 & \\
\hline $26-30$ & 1 & 1.2 & 0 & 0.0 & & 1 & 1.7 & 0 & 0.0 & \\
\hline$>30$ & 3 & 3.5 & 16 & 11.8 & & 3 & 5.1 & 6 & 2.6 & \\
\hline Unlimited & 13 & 15.3 & 10 & 7.4 & & 6 & 10.2 & 17 & 11.2 & \\
\hline Unclear answers & 7 & 8.2 & 24 & 17.6 & & 1 & 1.7 & 30 & 4.3 & \\
\hline No opinion & 11 & 12.9 & 13 & 9.6 & & 9 & 14.9 & 15 & 27.6 & \\
\hline
\end{tabular}

Table 4. Multiple logistic regression on number of accepted offspring after donation.

\begin{tabular}{|c|c|c|c|c|}
\hline & & \multicolumn{3}{|c|}{$\begin{array}{l}\text { Odds Ratio (OR) for accepting } 6 \text { or } \\
\text { more offspring vs. } 5 \text { or less offspring* }\end{array}$} \\
\hline & & OR & $95 \% \mathrm{Cl}(\mathrm{OR})$ & p-value \\
\hline \multirow[t]{2}{*}{ Sex } & Female & \multicolumn{3}{|c|}{ reference } \\
\hline & Male & 4.01 & $1.79-8.97$ & 0.001 \\
\hline Education & $\begin{array}{l}\text { Elementary/High school } \\
\text { University }\end{array}$ & 0.99 & $\begin{array}{l}0.52-1.90 \\
\text { reference }\end{array}$ & 0.990 \\
\hline \multirow[t]{3}{*}{ Marital status } & Single & 0.62 & $0.29-1.34$ & 0.228 \\
\hline & Partner & \multirow[t]{2}{*}{1.04} & $0.32-3.42$ & \multirow[t]{2}{*}{0.952} \\
\hline & Married/cohabiting & & reference & \\
\hline \multirow[t]{2}{*}{ Age } & $\leq 30$ & \multirow[t]{2}{*}{1.51} & $0.75-3.09$ & \multirow[t]{2}{*}{0.247} \\
\hline & $>30$ & & reference & \\
\hline \multirow[t]{2}{*}{ Biological children } & Yes & \multirow[t]{2}{*}{1.34} & $0.58-3.08$ & \multirow[t]{2}{*}{0.499} \\
\hline & No & & reference & \\
\hline
\end{tabular}

* Those with no opinion have been included in the group of 6 or more offspring. 
In Table 3 opinion of the acceptable number of offspring is displayed in relation to age and the donor having or not having biological children. Younger donors were as likely to allow a higher limit on offspring as older donors, and donors with biological children more frequently reported having no opinion about the acceptable number of offspring compared to those without children.

In the multiple logistic regression analysis the only significant relation with opinion on the acceptable number of children after donation was found to be with gender. Oocyte donors were four times more likely to accept a maximum of five children after donation compared to sperm donors, when controlling for age, educational level, marital status and biological children (Table 4).

\section{Discussion}

The donors reported a variety of opinions on the acceptable number of offspring that should be allowed from one donor, with oocyte donors expressing both more restrictive and more generous opinions compared to sperm donors. About half of both oocyte and sperm donors stated that the limit should be between one and ten offspring from one donor. About one fourth of donors had no firm opinion on the subject and being undecided appeared to be related to having biological children. When controlling for age, educational level, marital status and biological children, oocyte donors were more likely to support a limit of five offspring from one donor compared to sperm donors.

There are opinions that there is no need for a limit in the number of children to be allowed after gamete donation since the risk of accidental half-sibling unions may be close to zero (8). While this might be true there are also psychological and human factors to be taken into consideration for all parties involved as concerns what is optimal. For the donor there are of course different factors the donor might take into consideration in determining what a reasonable and acceptable number of offspring might be. Learning, for example, that the donated sperm from some individuals as reported in the media might have resulted in the birth of as many as 50 to 75 children (1) may influence the donor. For donors that have been exposed in the media as carrier of diseases that have a high probability to be inheritable the psychological and moral ethical dilemmas to be faced might become a great problem and even a personal tragedy. The disaster for families and the individuals and, most of all, for the child to be are also immeasurable psychologically, economically, and ethically. Society must be aware of this and be prepared for taking decisions or recommending decisions for consideration.

Motives for becoming an oocyte or sperm donor have been explored extensively worldwide and from various different perspectives including religion, laws, politics, and financial incentives. There could be financial motives for an individual's decision to donate numerous times, but the most frequently stated motive previously reported by gamete donors in the present study was "to help others", which is an altruistic motive (7).

Zweifel et al 2006, found that oocyte donors had a more restricted view on issues such as oocyte and embryo disposition after they have been through the donation program (9). This study together with Kalfoglou and Geller 2000, suggests that donors become more comfortable with expressing their opinions after they have donated and that women might have difficulties in fully imagining and conceptualising the implications of their donations (10). 
The percentage of women and men who do not know the results of their donation might change in the future. It may become more common for donors to try to obtain this information from the clinics. As a result of such information their opinions on setting a limit on the number off offspring from one donor might change. In Sweden, donors are informed of the offspring's legal right to obtain identifying information about the donor when sufficiently mature and donors are required to complete a document waiving them from all legal rights and responsibilities regarding offspring from their donation. Although identity-release donor programs have been operating in Sweden since 1985 and about 300 donor offspring are estimated to have reached the age of majority, relatively few appear to have requested information about their donor. One possible explanation for this situation is that significant groups of these offspring may not be aware of their conception by donor sperm. Also the impact of donors having children of their own as well as being engaged in new partner relationships might have an influence on the donors' future. The vast majority of the donors in our study had not donated in other settings. This might be due to the very limited reimbursement for donors in Sweden, the medical procedure or due to their feeling that they have made the contribution they wish to make and do not need do any more (7).

More research regarding disclosure to the children is needed, since a wide range or between $39-83 \%$ of parents who have had a semen donor intend to, or actually do, tell their offspring that they were conceived by sperm insemination (11-14). We also suspect that intending is one thing and doing or telling is a completely different matter. For instance Lalos et al (2007) showed that in their sample of 19 Swedish families $11(61 \%)$ of the parents had told their child about the donation but only six had revealed to the child that the child can obtain identification information about the donor (15).

A major strength of this study was that we had a very high participation rate and that it was a long-term follow-up on a national sample of donors. We have been able to follow these donors for between five and eight years after their donation which may be considered as a long time in research of this kind. However, in the group of donors we were not able to locate nine sperm donors who had changed their national identity number or who had a protected identity, as was the case for four of the female donors. How this might influence the identification process later merits future study.

\section{Conclusion}

Oocyte donors have a more restricted view on the acceptable number of offspring after donation compared to sperm donors. Donors perform a very humanitarian and societal act when donating their gametes to other couples or individuals. In the ambition to have safe and trustworthy donor programs we need to have well established regulations to be able to recruit donors in the future. In addition, the clinics should provide the donors and offspring as well as the receiving couples with a psychologically and genetically acceptable situation.

\section{Acknowledgement}

Financial support was received from Medical Research Council of Southeast Sweden and Swedish Research Council for Health, Working Life and Welfare. 


\section{References}

1. Hansen A. BMJ 2012;345;e6570

2. Jadva V, Freeman T, Kramer W, Golombok S. Sperm and oocyte donors' experiences of anonymous donation and subsequent contact with their donor offspring. Hum Reprod. 2011;26(3):638-45. Epub 2010 Dec 21.

3. Jadva V, Freeman T, Kramer W, Golombok S. Experiences of offspring searching for and contacting their donor siblings and donor. Reprod Biomed Online. 2010 ;20(4):523-32. Epub 2010 Jan 11.

4. Swedish National Board of Health and Welfare: SOSFS 2002:13; SOSAFS 2006:10

5. Sydsjö G, Lampic C, Brändström S, Gudmundsson J, Karlström P, Solensten N et al. Personality characteristics in a Swedish national sample of identifiable oocyte donors. BJOG. 2011;118(9):1067-1072.

6. Sydsjö G, Lampic C, Brändström S, Gudmundsson J, Karlström P, Solensten N et al. Who becomes a spermdonor: personality characteristics in a national samples of identifiable donors. BJOG. 2012;119(1):33-9. Epub 2011 Oct 18.

7. Svanberg AS, Lampic C, Geijerwall AL, Gudmundsson J, Karlström PO, Solensten NG et al. Gamete donors' motivation in a Swedish national sample: is there any ambivalence? A descriptive study. Acta Obstet Gynecol Scand. 2012;91(8):944-51.

8. Sawyer N. Sperm donor limits that control for the 'relative' risk associated with the use of open-identity donors. Hum Reprod. 2010 ;25(5):1089-96. Epub 2010 Feb 19.

9. Zweifel JE, Rathert MA, Klock SC, Walaski HP, Pritts EA, Olive DL et al. Comparative assessment of pre- and post-donation attitudes towards potential oocyte and embryo disposition and management among ovum donors in an oocyte donation programme. Hum Reprod. 2006;21(5):1325-7. Epub 2006 Jan 12.

10. Kalfoglou AL, Geller G. A follow-up study with oocyte donors exploring their experiences, knowledge, and attitudes about the use of their oocytes and the outcome of the donation. Fertil Steril. 2000;74(4):660-7.

11. Lindblad F, Gottlieb C, Lalos O. To tell or not to tell--what parents think about telling their children that they were born following donor insemination. J Psychosom Obstet Gynaecol. 2000;21(4):193-203.

12. Scheib JE, Riordan M, Rubin S. Choosing identity-release sperm donors: the parents' perspective 13-18 years later. Hum Reprod. 2003;18(5):1115-27.

13. Lycett E, Daniels K, Curson R, Golombok S. Offspring created as a result of donor insemination: a study of family relationships, child adjustment, and disclosure. Fertil Steril. 2004;82(1):172-9. 
14. Isaksson S, Sydsjö G, Skoog Svanberg A, Lampic C. Disclosure behaviour and intentions among 111 couples following treatment with oocytes or sperm from identityrelease donors: follow-up at offspring age 1-4 years. Hum Reprod. 2012;27(10):29983007. Epub 2012 Aug 1.

15. Lalos A, Gottlieb C, Lalos O. Legislated right for donor-insemination children to know their genetic origin: a study of parental thinking. Hum Reprod. 2007;22(6):175968. 